\title{
Effect of processing conditions on crystallinity and luminescent characteristics of aeschynite-type complex oxide crystals doped with $\mathrm{Dy}^{3+}$ and $\mathrm{Eu}^{3+}$
}

\author{
Masanori HIRANO ${ }^{1, \dagger}$, Ayana ODA $^{1}$ and Yuki TAKAGI ${ }^{1}$ \\ ${ }^{1}$ Department of Applied Chemistry, Faculty of Engineering, Aichi Institute of Technology, Yakusa, Toyota, Aichi 470-0392, Japan
}

Effect of processing conditions on the crystallinity and luminescent characteristics of aeschynite-type Dy ${ }^{3+}$ - and $\mathrm{Eu}^{3+}$-doped $\mathrm{GdTiNbO}_{6}$ formed under hydrothermal conditions from precursor solutions of inorganic salts, i.e. $\mathrm{Dy}\left(\mathrm{NO}_{3}\right)_{3}, \mathrm{EuCl}_{3}, \mathrm{GdCl}_{3}, \mathrm{TiOSO}_{4}$, and $\mathrm{NbCl}_{5}$ was investigated. A processing condition using the hydrolysis of urea promoted the formation of aeschynite with finer crystallite due to an increase in nucleation number. The aeschynite-type solid solution was directly formed under hydrothermal conditions at $240^{\circ} \mathrm{C}$ because its lattice parameters changed according to the Vegard's Law. The photoluminescence (PL) emission intensity of aeschynite crystals depended on their crystallinity, which was closely related to their processing conditions. Without subsequent heat treatment in air, the as-prepared aeschynite-type solid solutions substitutionally doped with $5 \mathrm{~mol} \% \mathrm{Dy}^{3+}$ and $50 \mathrm{~mol} \% \mathrm{Eu}^{3+}$ showed the maximum and intense PL emissions under direct excitation of dopant ions. In the case of indirect excitation using energy transfer from the host absorption band at $280 \mathrm{~nm}$, the characteristic blue and yellow PL emission intensities involved in the broad host emission of the Dy ${ }^{3+}$-doped $\mathrm{GdTiNbO}_{6}$ were improved dramatically after heating at $1300^{\circ} \mathrm{C}$ in air.

(02019 The Ceramic Society of Japan. All rights reserved.

Key-words : Aeschynite, Rare earth, Hydrothermal synthesis, Photoluminescence

\section{Introduction}

Materials based on metal complex oxides with general formula $\mathrm{A}^{3+} \mathrm{B}^{4+} \mathrm{C}^{5+} \mathrm{O}_{6}$ in ternary systems (i.e. $\mathrm{A}_{2} \mathrm{O}_{3}-$ $2 \mathrm{BO}_{2}-\mathrm{C}_{2} \mathrm{O}_{5}$ ) have attracted attention because of interesting characteristics and high potentials such as dielectric ${ }^{1)}$ and microwave dielectric properties, ${ }^{2)}$ strong relaxor ferroelectric behavior, ${ }^{3)}$ and photoluminescence (PL) properties. ${ }^{4)}$ The single phase occurrence, ${ }^{5)}$ structures, ${ }^{6)}$ and properties of these complex oxides have been investigated by some researchers. ${ }^{7)}$ In these compounds, several complex oxides of $\mathrm{RETiNbO}_{6}$, where $\mathrm{RE}$ is a rare earth, have been studied for the development of dielectric resonators, ${ }^{8)-11)}$ solid-state laser materials, ${ }^{12), 13)}$ and phosphors. ${ }^{7), 14)-17)} \mathrm{RETiNbO}_{6}$ has mainly both structures, i.e. aeschynite and euxenite depending on the radius of $\mathrm{RE}^{3+}$ ion, and these phases are usually members of representative crystalline minerals containing rare earth element.

In recent years, luminescent rare earth ions-doped materials have attracted much attention because they can be used in many highly functional applications, e.g., display devices (: field emission displays, cathode ray tubes, and vacuum fluorescent displays), solid-state laser, biological

\footnotetext{
Corresponding author: M. Hirano; E-mail: hirano@aitech. ac.jp
}

labeling devices, biochemical probes, and lighting apparatus such as white light-emitting diodes. ${ }^{18)-22)} \mathrm{Dy}^{3+}$ doped materials are known to emit blue light at 470 $500 \mathrm{~nm}$ and yellow light at $570-600 \mathrm{~nm}$ attributed to the ${ }^{4} F_{9 / 2} \rightarrow{ }^{6} H_{15 / 2}$ and ${ }^{4} F_{9 / 2} \rightarrow{ }^{6} H_{13 / 2}$ transitions, respectively under UV excitation. Trivalent $\mathrm{Eu}^{3+}$ ion possesses a typical feature as a representative activator for red emission because its emission band is centered about the primary red color, on the other hand. ${ }^{23)}$

$\mathrm{RETiNbO}_{6}$ crystals among those complex oxide materials have been synthesized mostly by means of conventional solid-state reactions or processes such as solution combustion technique, i.e., Pechini method and polymerized complex method or sol-gel method, ${ }^{15), 24)-27)}$ excluding a few techniques based on aqueous solutions, ${ }^{28), 29)}$ in general. However, in those reactions and processes, subsequent heating at high temperatures (more than about $1000^{\circ} \mathrm{C}$ ) in air is indispensable for the formation or crystallization of desired metal complex oxide crystals. Recently, from the view point of processing through energy consumption reduction, much attention has been devoted on green processing at low temperatures including wet chemical synthesis routes for the synthesis of fine inorganic crystals because those routes such as hydrothermal synthesis method are advantageous to obtain highly homogeneous materials and to control the crystallinity and 
particle size of fine powders based on metal oxides, complex oxides, new compounds, solid solutions, and metastable phases. ${ }^{30)-34)}$ Since GdTiNbO$_{6}$-based compounds crystallize into euxenite-type structure by means of heattreatment at high temperatures of $1000-1400^{\circ} \mathrm{C}$ in air in the case of the solid-state reactions, in general, almost all of reports and literatures published on $\mathrm{GdTiNbO}_{6}$-based compounds up to now are studies and data concerning the euxenite-type $\mathrm{GdTiNbO}_{6}{ }^{35}$ ) with the exception of our study. Therefore, there are few reports and data that are available on the aeschynite-type $\mathrm{GdTiNbO}_{6}$-based materials, e.g. $\mathrm{Dy}^{3+}$-doped $\mathrm{GdTiNbO}_{6}$. Because there are only a few studies on the low-temperature synthesis of fine GdTiNbO $_{6}$-based crystals, on the other hand, the relationship between processing and properties of fine $\mathrm{GdTiNbO}_{6}$ phosphor materials using hydrothermal route at low temperatures less than $250^{\circ} \mathrm{C}$ has not been sufficiently clarified.

In this study, the effect of processing conditions on the direct synthesis, structure, and luminescence properties of aeschynite-type $\mathrm{Dy}^{3+}$-doped $\mathrm{GdTiNbO}_{6}$ and $\mathrm{Eu}^{3+}$-doped $\mathrm{GdTiNbO}_{6}$ fine crystals has been investigated using a green processing under mild hydrothermal conditions from precursor solutions of inorganic salts.

\section{Experimental procedures}

\subsection{Preparation of samples}

Two metal complex oxides [composition: $\mathrm{Dy}_{x} \mathrm{Gd}_{1-x^{-}}$ $\mathrm{TiNbO}_{6}(x=0-0.20)$ and $\left.\mathrm{Eu}_{x} \mathrm{Gd}_{1-x} \mathrm{TiNbO}_{6}(x=0-1.00)\right]$ were synthesized using hydrothermal method. A solution mixture of an aqueous solution selected from reagentgrade $\mathrm{Dy}\left(\mathrm{NO}_{3}\right)_{3} \cdot 5 \mathrm{H}_{2} \mathrm{O}, \quad \mathrm{EuCl}_{3} \cdot 6 \mathrm{H}_{2} \mathrm{O}, \quad \mathrm{GdCl}_{3} \cdot 6 \mathrm{H}_{2} \mathrm{O}$, $\mathrm{TiOSO}_{4}$, and an ethanol solution of $\mathrm{NbCl}_{5}$ in different ratios of $\mathrm{Dy} / \mathrm{Gd} / \mathrm{Ti} / \mathrm{Nb}=x / 1.00-x / 1.00 / 1.00, \quad x=$ $0-0.20$, or $\mathrm{Eu} / \mathrm{Gd} / \mathrm{Ti} / \mathrm{Nb}=x / 1.00-x / 1.00 / 1.00, x=$ $0-1.00$ was prepared in a Teflon container $\left(100 \mathrm{~cm}^{3}\right)$ while stirring. Two-types of precursor solutions were prepared by the addition of (i) aqueous ammonia or (ii) aqueous solution of urea into the solution mixture while stirring. These solutions were controlled to obtain weak basic conditions after hydrothermal treatment by the addition of aqueous ammonia or hydrolysis of urea. The precursor solution $\left(90 \mathrm{~cm}^{3}\right)$ with total cation concentration of 0.500 $\mathrm{mol} / \mathrm{dm}^{3}$ (: $\mathrm{Dy}+\mathrm{Gd}+\mathrm{Ti}+\mathrm{Nb}$ or $\mathrm{Eu}+\mathrm{Gd}+\mathrm{Ti}+$ $\left.\mathrm{Nb}=0.500 \mathrm{~mol} / \mathrm{dm}^{3}\right)$ in the Teflon container was then placed in a stainless-steel vessel. The vessel was tightly sealed and heated at $200-240^{\circ} \mathrm{C}$ for $5-24 \mathrm{~h}$ while rotating at $1.5 \mathrm{rpm}$. After the hydrothermal treatment, precipitates formed in the Teflon container were washed with distilled water until the $\mathrm{pH}$ value of the rinsed water became 7.0, separated from the solution by centrifugation, and dried in an oven at $60^{\circ} \mathrm{C}$. The powders thus prepared hydrothermally were heated in an alumina crucible at a heating rate $200^{\circ} \mathrm{C} / \mathrm{h}$, kept at $1000-1300^{\circ} \mathrm{C}$ for $1 \mathrm{~h}$ in air, and then cooled to room temperature in a furnace.

\subsection{Characterization}

$\mathrm{X}$-ray diffraction (XRD) patterns of as-prepared pow- ders were recorded using $\mathrm{Cu} \mathrm{K} \alpha$ radiation (XRD; model RINT-2000, Rigaku, Tokyo, Japan). The crystallite size of the orthorhombic aeschynite phase was estimated from the line broadening of 020 diffraction peak, according to the Scherrer equation, $D_{\mathrm{XRD}}=K \lambda / \beta \cos \theta$, where $\theta$ is the Bragg angle of diffraction lines; $K$ is a shape factor $(K=$ 0.9 in this work); $\lambda$ is the wavelength of incident $\mathrm{X}$-rays, and $\beta$ is the corrected half-width given by $\beta^{2}=\beta_{m}{ }^{2}-\beta_{s}{ }^{2}$, where $\beta_{m}$ is the measured half-width and $\beta_{s}$ is the halfwidth of a standard sample. The lattice parameters were measured using silicon as the internal standard. The observation of the morphology of as-prepared samples was carried out using scanning electron microscope (FESEM; model JSM-6335FM, JEOL, Tokyo, Japan) and transmission electron microscope (TEM; model JEM-2100Plus, JEOL, Tokyo, Japan) equipped with an energy dispersive $\mathrm{X}$-ray spectrometry (EDS).

The ultraviolet-visible (UV-Vis) absorption spectra of the prepared powders were recorded at room temperature by means of UV-Vis spectrophotometer with an integrating sphere attachment (V-560, Nihon Bunko, Tokyo, Japan). The measurements of the PL emission and excitation spectra of samples were performed using a spectrofluorometer (F-2700, Hitachi High-Tech, Tokyo, Japan) with a Xe lamp. Powder samples doped with $\mathrm{Dy}^{3+}$ and $\mathrm{Eu}^{3+}$ were excited with 280,387 and $317,394 \mathrm{~nm}$ radiation from a $150 \mathrm{~W}$ xenon lamp, respectively. All measurements were carried out at room temperature. The emission wavelength was scanned from 500 to $750 \mathrm{~nm}$ at a scanning rate of $60 \mathrm{~nm} / \mathrm{min}$. For the measurements of the excitation spectra, the excitation wavelength was scanned from 220 to $500 \mathrm{~nm}$ at the same scanning rate, and emission monitored at $483 \mathrm{~nm}$ for $\mathrm{GdTiNbO}_{6}: \mathrm{Dy}^{3+}$ and $611 \mathrm{~nm}$ for $\mathrm{GdTiNbO}_{6}: \mathrm{Eu}^{3+}$, respectively. The absolute PL quantum yield of the samples was measured under excitation at 394 and $464 \mathrm{~nm}$ using an absolute quantum yield spectrometer (Quantaurus-QY Plus C13534-02, Hamamatsu Photonics K.K., Hamamatsu, Japan). The fluorescence decay curves were measured using a Quantaurus-tau C11367 fluorescence lifetime spectrometer (Hamamatsu Photonics K.K., Hamamatsu, Japan).

\section{Results and discussion}

\subsection{Effect of processing conditions on the} formation of aeschynite-type fine crystals

The hydrothermal treatment of the precursor solution was performed under weak basic conditions in the presence of aqueous ammonia or urea for 5-24h. Figure 1 shows the XRD patterns of precipitates (composition: $\mathrm{Eu}_{0.50} \mathrm{Gd}_{0.50} \mathrm{TiNbO}_{6}$ ) formed under hydrothermal conditions in the presence of aqueous ammonia or urea at 200$240^{\circ} \mathrm{C}$ for $5 \mathrm{~h}$. After hydrothermal treatment at $200^{\circ} \mathrm{C}$, the product was amorphous. The hydrothermal crystallization of an aeschynite phase from amorphous precipitate was occurred around $220^{\circ} \mathrm{C}$. When the treatment temperature is raised to $240^{\circ} \mathrm{C}$, almost a single phase of aeschynite with high crystallinity was formed in the presence of aqueous ammonia. As suggested from the line broadening of the 
- Aeschynite-type

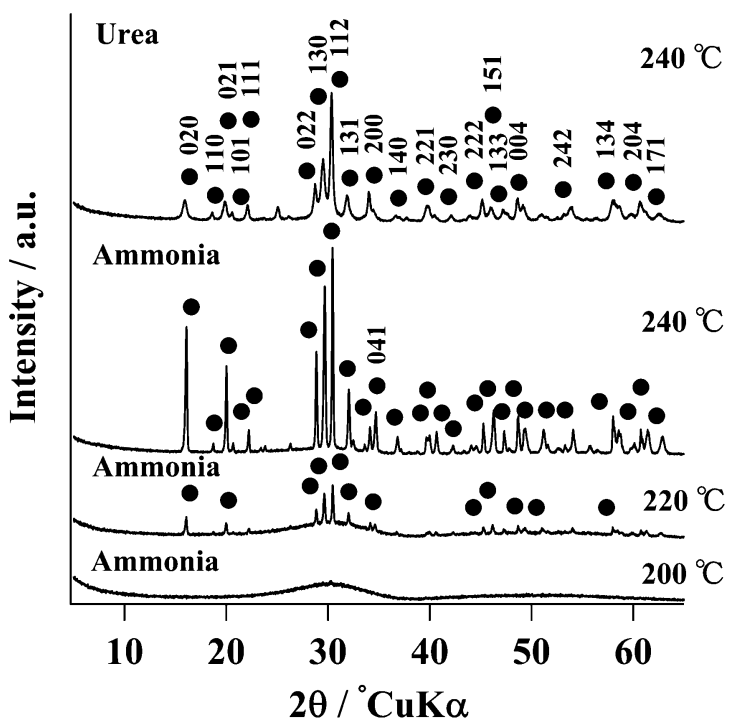

Fig. 1. XRD patterns of precipitates $\left(: \mathrm{Eu}_{0.50} \mathrm{Gd}_{0.50} \mathrm{TiNbO}_{6}\right)$ obtained under hydrothermal conditions in the presence of urea or aqueous ammonia at $200-240^{\circ} \mathrm{C}$ for $5 \mathrm{~h}$.

Table 1. Crystallite size, emission $\left({ }^{5} \mathrm{D}_{0} \rightarrow{ }^{7} \mathrm{~F}_{2}\right)$ intensity at 510 $\mathrm{nm}$, and absolute quantum yield (excitation at $394 \mathrm{~nm}$ ) of aeschynite-type $\mathrm{Gd}_{1.00-x} \mathrm{Eu}_{x} \mathrm{TiNbO}_{6}$ formed under several processing conditions at $240^{\circ} \mathrm{C}$ using hydrothermal method

\begin{tabular}{lccc}
\hline & As-prepared sample (composition $x=0.50)$ \\
\hline Processing condition & Urea 5h & Ammonia 5 & Ammonia 24h \\
\hline Crystallite size (nm) & 18 & 53 & 58 \\
Emission Intensity (a.u.) & 4691 & 8409 & 9768 \\
Quantum yield (\%) & 21 & 37 & 32 \\
\hline
\end{tabular}

XRD peak, finer aeschynite crystals were formed when using the hydrolysis of urea, on the other hand. In Table 1, the crystallite sizes of these aeschynite phases are shown. The crystallite size of the aeschynite prepared by using the hydrolysis of urea was one-third of that obtained in the presence of aqueous ammonia. This is considered to be mainly due to an increase in the nucleation number for the crystallization of aeschynite. The nucleation of aeschynite may be accelerated by homogeneous and rapid generation of hydroxide ions by hydrolysis of urea at more than about $90^{\circ} \mathrm{C}$.

Figures 2(a) and 2(b) present the XRD patterns of precipitates, $\mathrm{Dy}_{x} \mathrm{Gd}_{1.00-x} \mathrm{TiNbO}_{6}, x=0-0.10$ and $\mathrm{Eu}_{x} \mathrm{Gd}_{1.00-x^{-}}$ $\mathrm{TiNbO}_{6}, x=0-1.00$, respectively, which were formed from the precursor solutions with various compositions under hydrothermal conditions at $240^{\circ} \mathrm{C}$ in the presence of aqueous ammonia. The XRD patterns suggest that all of the precipitates were synthesized as a single phase corresponding to the aeschynite-type structure. The $\mathrm{RETiNbO}_{6}$ oxides are known to possess two characteristic crystalline forms of orthorhombic structure depending on the ionic radius of $\mathrm{RE}^{3+}$. One is the aeschynite structure with a space group symmetry Pnma and the other is the euxenite structure belonging to a Pbcn symmetry. According to the (a)

- Aeschynite-type
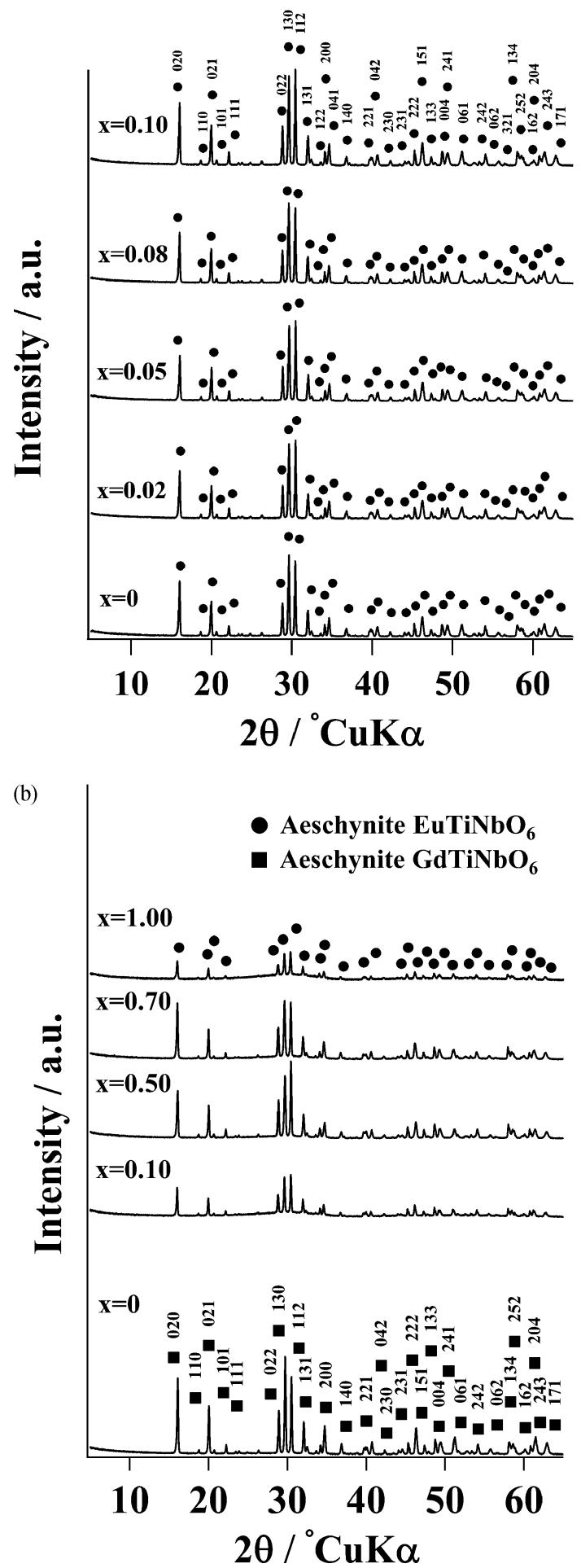

Fig. 2. XRD patterns of precipitates obtained at various compositions (a) $x=0-0.10$ in the $\mathrm{Dy}_{x} \mathrm{Gd}_{1.00-x} \mathrm{TiNbO}_{6}$ system under hydrothermal conditions in the presence of aqueous ammonia at $240^{\circ} \mathrm{C}$ for $24 \mathrm{~h}$ and (b) $x=0-1.00$ in the $\mathrm{Eu}_{x} \mathrm{Gd}_{1.00-x} \mathrm{TiNbO}_{6}$ system under hydrothermal conditions in the presence of aqueous ammonia at $240^{\circ} \mathrm{C}$ for $5 \mathrm{~h}$.

literatures, ${ }^{12), 13), 36), 37)}$ GdTiNbO $_{6}$ [at the composition $x=0$ in Figs. 2(a) and 2(b)] and $\mathrm{DyTiNbO}_{6}$ are suggested to belong to the euxenite-type phase and $\mathrm{EuTiNbO}_{6}$ [in the 


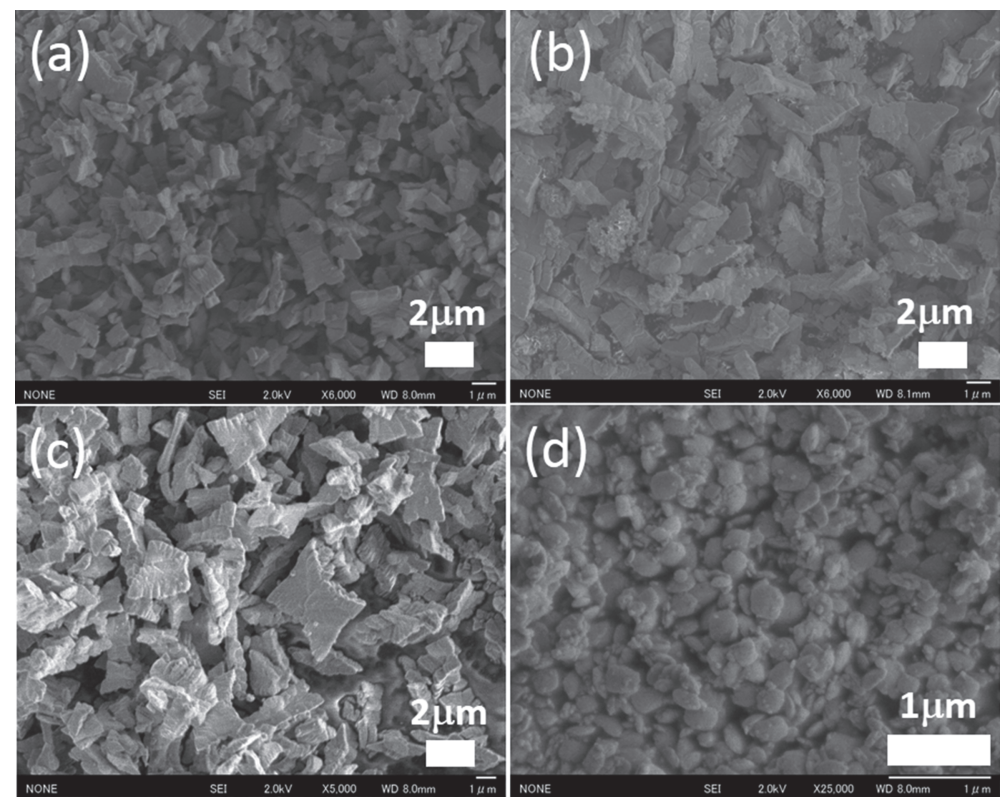

Fig. 3. FESEM images of samples formed hydrothermally at various conditions: (a) $\mathrm{GdTiNbO}_{6}$ at $240^{\circ} \mathrm{C}$ for $5 \mathrm{~h}$, using aqueous ammonia (b) $\mathrm{Eu}_{0.50} \mathrm{Gd}_{0.50} \mathrm{TiNbO}_{6}$ at $240^{\circ} \mathrm{C}$ for $5 \mathrm{~h}$, using aqueous ammonia, (c) $\mathrm{Dy}_{0.05} \mathrm{Gd}_{0.95^{-}}$ $\mathrm{TiNbO}_{6}$ at $240^{\circ} \mathrm{C}$ for $24 \mathrm{~h}$, using aqueous ammonia, and (d) $\mathrm{Eu}_{0.50} \mathrm{Gd}_{0.50} \mathrm{TiNbO}_{6}$ at $240^{\circ} \mathrm{C}$ for $5 \mathrm{~h}$, using urea.

composition $x=1.00$ in Fig. 2(b)] is supposed to possess the aeschynite-type structure as the most stable phase at room temperature under normal pressure. It is noted that a single phase corresponding to the aeschynite-type phase, that is, orthorhombic $\mathrm{CaTa}_{2} \mathrm{O}_{6}$-type structure belonging to the Pnma space group was formed directly in all of the compositions including pure $\mathrm{GdTiNbO}_{6}$ under these hydrothermal conditions.

The FESEM images of precipitates corresponding to the composition $\mathrm{GdTiNbO}_{6}, \mathrm{Eu}_{0.50} \mathrm{Gd}_{0.50} \mathrm{TiNbO}_{6}$, and $\mathrm{Dy}_{0.05} \mathrm{Gd}_{0.95} \mathrm{TiNbO}_{6}$ that were obtained at $240^{\circ} \mathrm{C}$ in the presence of aqueous ammonia are shown in Figs. 3(a)3(c), respectively. The images of the products suggest that those particles possess rectangular-like morphology, and that they are micron-sized in the range of 1.5-5 $\mu \mathrm{m}$-length and 1-2 $\mu \mathrm{m}$-width and well-crystallized. The length of each product is about two-times larger than its width. The $x$ letter-like morphology is also observed in the FESEM images. In the samples formed under the same hydrothermal condition, the particle size of $\mathrm{Eu}^{3+}$-doped sample [Fig. 3(b)] became a little bit large in comparison with that of pure $\mathrm{GdTiNbO}_{6}$ [Fig. 3(a)]. The $\mathrm{Dy}^{3+}$-doped sample [Fig. 3(c)] that was synthesized by hydrothermal treatment for $24 \mathrm{~h}$ grew larger than those formed by treatment for $5 \mathrm{~h}$. Those products are considered to be polycrystalline because the crystallite size value for the $\mathrm{Eu}_{0.50} \mathrm{Gd}_{0.50^{-}}$ $\mathrm{TiNbO}_{6}$ sample evaluated from the XRD line broadening is $53 \mathrm{~nm}$ (Table 1). Figure 3(d) shows the FESEM image of $\mathrm{Eu}_{0.50} \mathrm{Gd}_{0.50} \mathrm{TiNbO}_{6}$ precipitate obtained by hydrothermal treatment at $240^{\circ} \mathrm{C}$ for $5 \mathrm{~h}$ in the presence of urea. Relatively homogeneous and submicron-sized particles less than $0.4 \mu \mathrm{m}$ are observed when using the hydrolysis of urea. Their crystallite size was $18 \mathrm{~nm}$ as shown in Table 1. These FESEM observation results relatively well corre- sponded to their features of XRD patterns shown in Fig. 1. The TEM-EDS mapping of the as-prepared GdTiNbO sample are presented in Fig. 4. The elemental mapping images of $\mathrm{Ti}, \mathrm{Nb}$, and $\mathrm{Gd}$ demonstrate that these samples formed directly under hydrothermal conditions possess homogeneity in elemental distribution.

The effect of hydrothermal treatment time on the crystallinity of product was investigated. The prolonged hydrothermal treatment for $24 \mathrm{~h}$ was conducted at $240^{\circ} \mathrm{C}$ to improve the crystallinity of aeschynite-type (Eu, Gd)$\mathrm{TiNbO}_{6}$. The crystalline products formed after hydrothermal treatment for $24 \mathrm{~h}$ were compared with those obtained after hydrothermal treatment for $5 \mathrm{~h}$. The XRD patterns of precipitates (composition: $\mathrm{Eu}_{0.50} \mathrm{Gd}_{0.50} \mathrm{TiNbO}_{6}$ ) obtained under hydrothermal conditions at $240^{\circ} \mathrm{C}$ for 5 and $24 \mathrm{~h}$ are shown in Fig. 5. Both the precipitates were identified as aeschynite-type phase with good crystallinity. The crystallite sizes evaluated from the XRD line broadening of 020 diffraction peak of aeschynite phase formed by hydrothermal treatment for 5 and $24 \mathrm{~h}$ were 53 and $58 \mathrm{~nm}$, respectively as shown in Table 1 . It is obvious that the aeschynite-type product formed via prolonged hydrothermal treatment possess higher crystallinity because the sharper/higher the peaks are, the more crystalline the sample become, in general.

The prolonged hydrothermal treatment for $24 \mathrm{~h}$ was carried out at $240^{\circ} \mathrm{C}$ for precursor solutions (composition: $\left.\mathrm{Eu}_{x} \mathrm{Gd}_{1.00-x} \mathrm{TiNbO}_{6}, \quad x=0-1.00\right)$ to measure precisely lattice parameters of samples. All of the precipitates were formed as aeschynite phase. The detail observation of the XRD patterns, together with the XRD lines of the internal standard Si showed that the XRD lines gradually shifted to lower degree of $2 \theta$ corresponding to an increase in $\mathrm{Eu}^{3+}$ concentration. This observed shift into lower $2 \theta$ values 

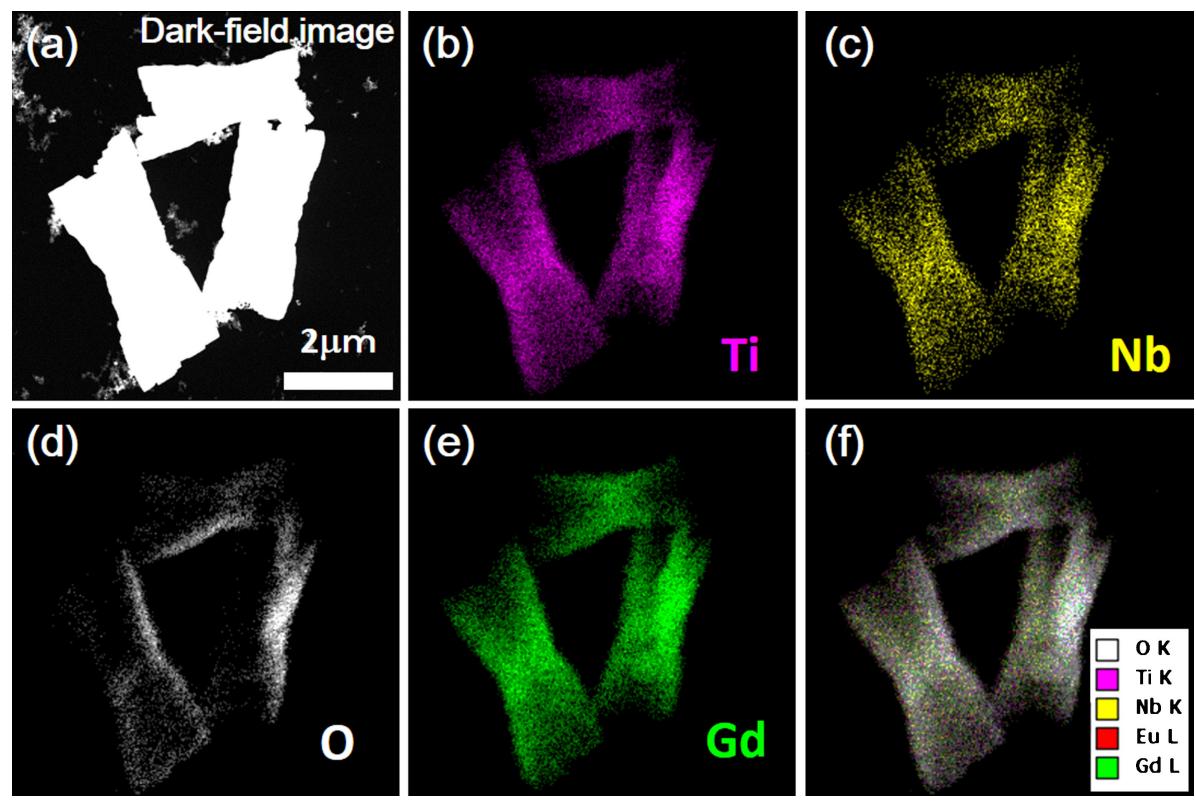

Fig. 4. (a)-(f) TEM-EDS mapping of $\mathrm{GdTiNbO}_{6}$ sample formed by hydrothermal treatment using aqueous ammonia at $240^{\circ} \mathrm{C}$ for $5 \mathrm{~h}$.

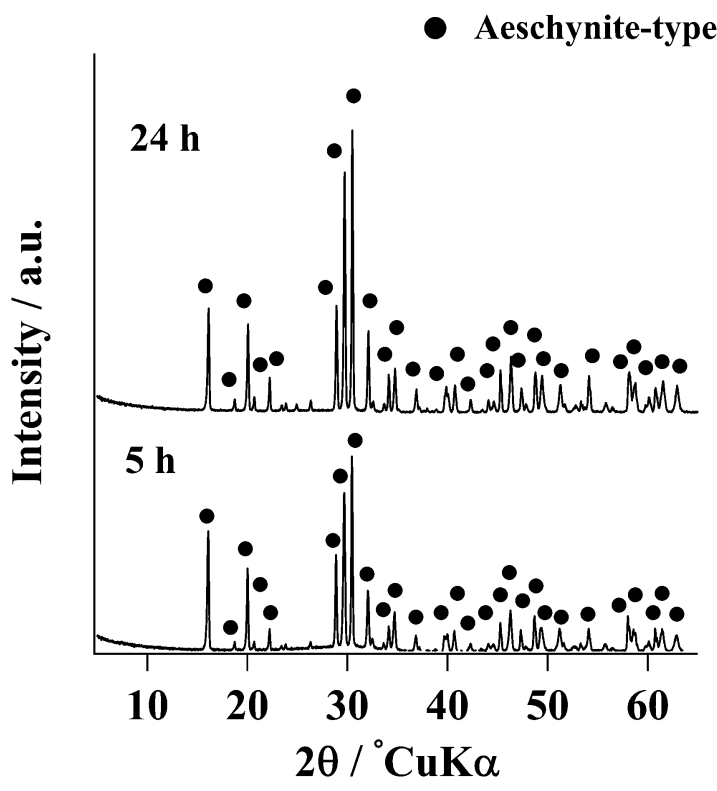

Fig. 5. XRD patterns of precipitates (: $\mathrm{Eu}_{0.50} \mathrm{Gd}_{0.50} \mathrm{TiNbO}_{6}$ ) obtained under hydrothermal conditions in the presence of aqueous ammonia at $240^{\circ} \mathrm{C}$ for 5 and $24 \mathrm{~h}$.

with an increase in $\mathrm{Eu}^{3+}$ suggests an increase in lattice parameters. The lattice parameters of the as-prepared aeschynite-type $\mathrm{Eu}_{x} \mathrm{Gd}_{1.00-x} \mathrm{TiNbO}_{6}$ precipitates evaluated as orthorhombic structure plotted against $x$ : the concentration of $\mathrm{Eu}^{3+}$ are presented in Fig. 6. The lattice parameters $a_{0}$ and $c_{0}$ of the orthorhombic aeschynite phase gradually and linearly increased in particular as the concentration of substitution with $\mathrm{Eu}^{3+}$ increased. This change in the lattice parameters of aeschynite phase in the asprepared nanocrystals nearly corresponded to the Vegard's Law, which is due to the increase of ionic radius from $0.1053 \mathrm{~nm}$ for $\mathrm{Gd}^{3+}$ to $0.1066 \mathrm{~nm}$ for the $\mathrm{Eu}^{3+} .{ }^{38)}$ It is

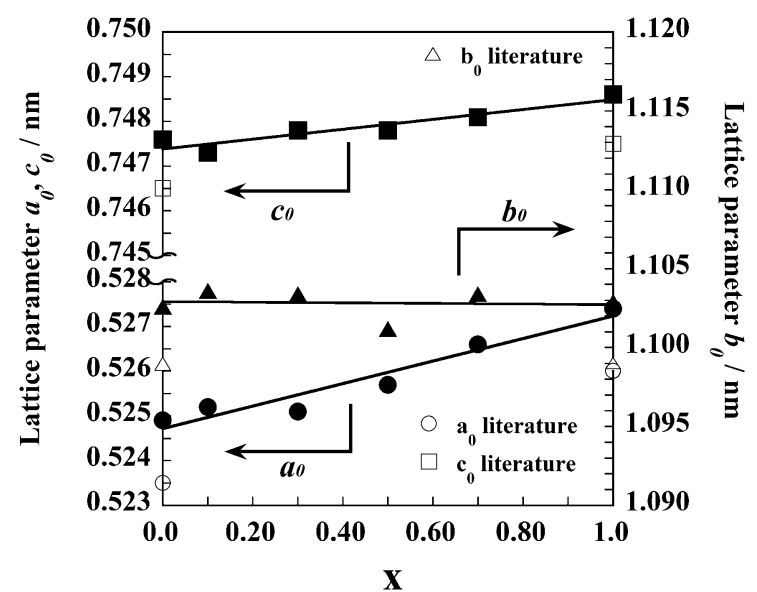

Fig. 6. Lattice parameters plotted against $\mathrm{Eu}^{3+}$ concentration, $x$ for $\mathrm{Eu}_{x} \mathrm{Gd}_{1.00-x} \mathrm{TiNbO}_{6}$ prepared under hydrothermal conditions in the presence of aqueous ammonia at $240^{\circ} \mathrm{C}$ for $24 \mathrm{~h}$.

evident that a complete solid solution with aeschynite-type structure in the $\mathrm{EuTiNbO}_{6}-\mathrm{GdTiNbO}_{6}$ system was formed directly under hydrothermal conditions at $240^{\circ} \mathrm{C}$.

Similar change in the lattice parameters of aeschynitetype precipitates is considered to occur in the $\mathrm{DyTiNbO}_{6}-$ $\mathrm{GdTiNbO}_{6}$ system. However, the concentration range of $\mathrm{Dy}^{3+}$ substitutionally doped into $\mathrm{GdTiNbO}_{6}$ was onetenth of that in the EuTiNbO $6-\mathrm{GdTiNbO}_{6}$ system in this experiment. Therefor the corresponding lattice parameter changes would become small and to find the changes in the lattice parameters is considered to be difficult because the concentration change ratio is small. In this study, certain existence of $\mathrm{Dy}^{3+}$ dopant in the sample doped with the lowest $\mathrm{Dy}^{3+}$, i.e. the sample $x=0.02$ in the $\mathrm{DyTiNbO}_{6}-$ $\mathrm{GdTiNbO}_{6}$ system was confirmed by the measurements of the excitation spectra and PL emission spectra in the sample $x=0.02$ in the next section [Figs. 8(a) and 9(a)]. Since 


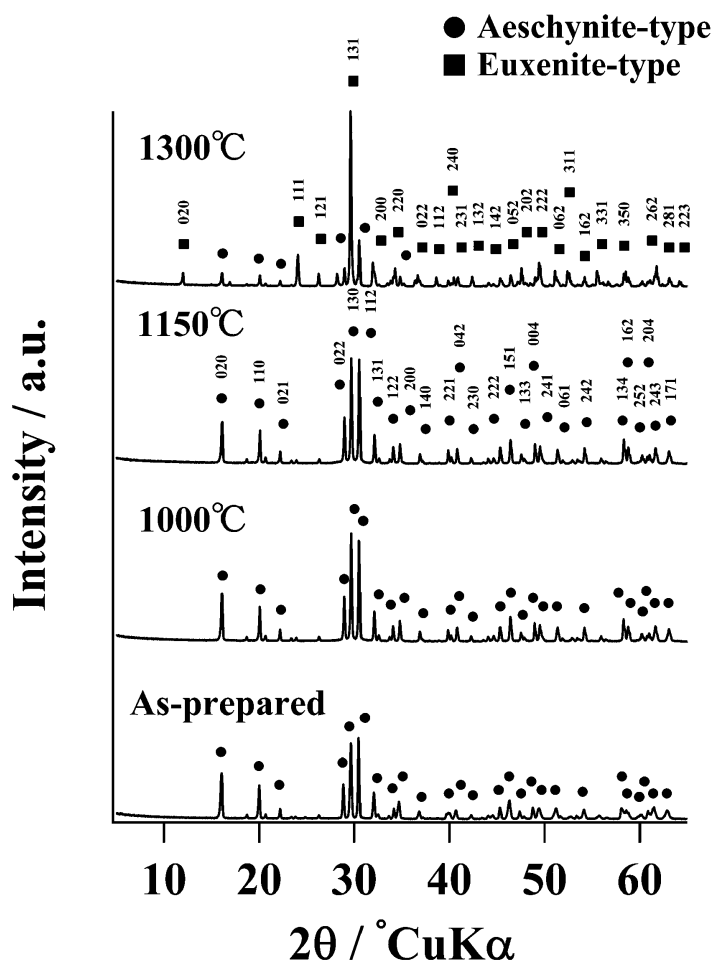

Fig. 7. XRD patterns of $\mathrm{Dy}_{0.05} \mathrm{Gd}_{0.95} \mathrm{TiNbO}_{6}$ samples before and after heating at $1000-1300^{\circ} \mathrm{C}$ for $1 \mathrm{~h}$ in air.

$\mathrm{GdTiNbO}_{4}$ (in the composition $x=0$ ) has a euxenite-type structure as a stable phase, the aeschynite-type phase in the composition range rich in $\mathrm{GdTiNbO}_{4}$ is suggested to be metastable one. What needs to be emphasized is that the aeschynite-type phase is formed in the whole composition range under this hydrothermal condition.

The formation of $\mathrm{GdTiNbO}_{6}$-based compound substitutionally doped with $5 \mathrm{~mol} \% \mathrm{Dy}^{3+}$ was done hydrothermally at $240^{\circ} \mathrm{C}$ for $24 \mathrm{~h}$. Then, the as-prepared precipitate doped with $5 \mathrm{~mol} \% \mathrm{Dy}^{3+}$ was heated at $1000-1300^{\circ} \mathrm{C}$ for $1 \mathrm{~h}$ in air. The XRD patterns of the as-prepared sample correspond to the composition $\mathrm{Dy}_{0.05} \mathrm{Gd}_{0.95} \mathrm{TiNbO}_{6}$ and samples after heating in air are also indicated in Fig. 7. The as-prepared sample and samples after heating at 1000 and $1150^{\circ} \mathrm{C}$ were detected as orthorhombic aeschynite-type structure. However, heating at $1300^{\circ} \mathrm{C}$ in air promoted the occurrence and progression of the phase transition from aeschynite to euxenite structure. The main crystalline phase of $\mathrm{Dy}_{0.05} \mathrm{Gd}_{0.95} \mathrm{TiNbO}_{6}$ formed by heating at $1300^{\circ} \mathrm{C}$ was euxenite. The euxenite structure is suggested to be stable phase for $\mathrm{Dy}_{0.05} \mathrm{Gd}_{0.95} \mathrm{TiNbO}_{6}$. This result is suggested to be reasonable according to the literatures ${ }^{12), 13), 36), 37)}$ because the average ionic radius of $\left(\mathrm{Dy}_{0.05} \mathrm{Gd}_{0.9}\right)^{3+}$ was smaller than that of $\mathrm{Gd}^{3+}$. The dependences of phase transition upon both $\mathrm{Eu}^{3+}$ concentration and heating temperature in air were already investigated, on the other hand. ${ }^{39)}$

3.2 Optical and luminescence properties of as-prepared aeschynite-type fine crystals

The UV-Vis absorption spectra of the as-prepared aeschynite-type $\mathrm{Dy}_{x} \mathrm{Gd}_{1.00-x} \mathrm{TiNbO}_{6}$ and $\mathrm{Eu}_{x} \mathrm{Gd}_{1.00-x^{-}}$
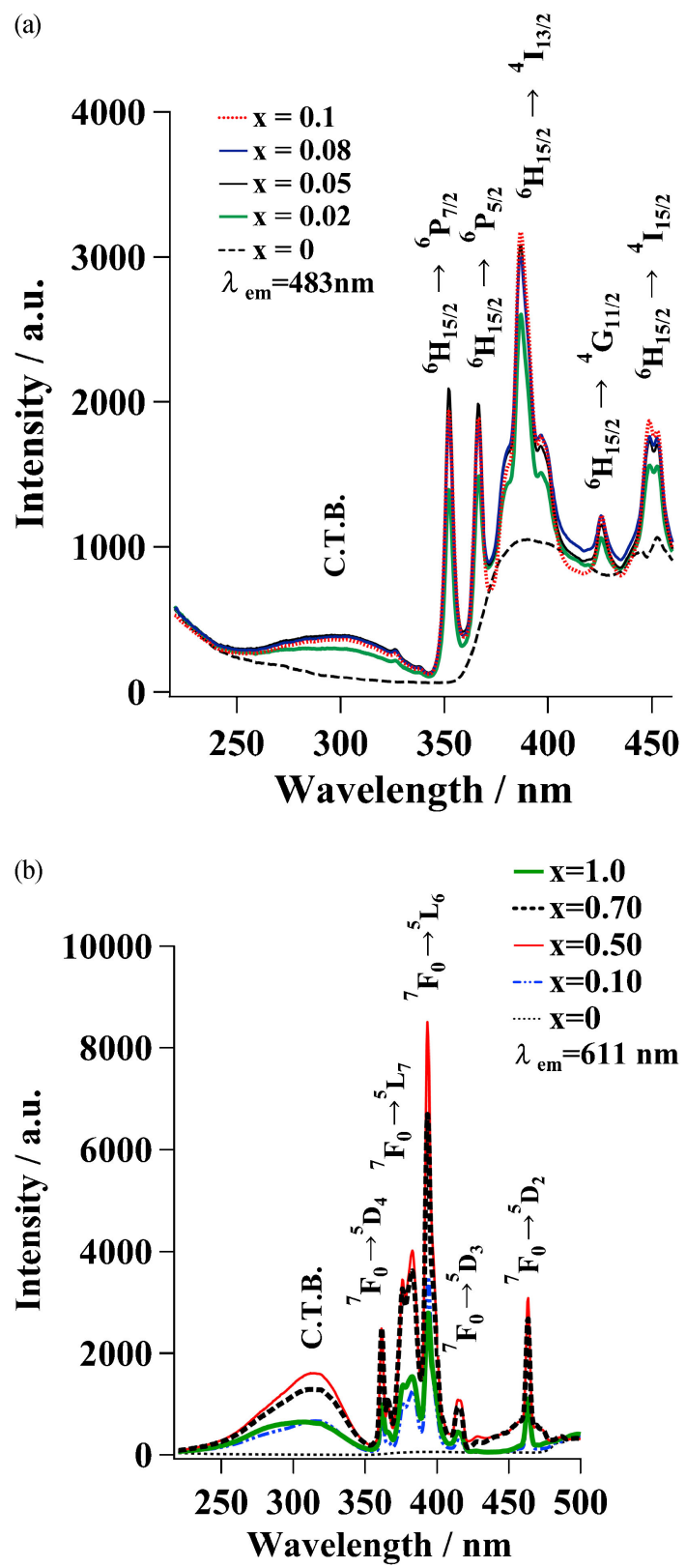

Fig. 8. Excitation spectra measured by (a) monitoring at $483 \mathrm{~nm}$ for $\mathrm{Dy}_{x} \mathrm{Gd}_{1.00-x} \mathrm{TiNbO}_{6}$ samples and by (b) monitoring at $611 \mathrm{~nm}$ for $\mathrm{Eu}_{x} \mathrm{Gd}_{1.00-x} \mathrm{TiNbO}_{6}$ samples formed under hydrothermal conditions in the presence of aqueous ammonia at $240^{\circ} \mathrm{C}$ for 24 and $5 \mathrm{~h}$, respectively.

$\mathrm{TiNbO}_{6}$ precipitates formed at $240^{\circ} \mathrm{C}$ were recorded. In the spectra, the appearances of several small absorbance peaks attributed to the $\mathrm{f}-\mathrm{f}$ transitions of $\mathrm{Dy}^{3+}$ and $\mathrm{Eu}^{3+}$ in the samples containing dysprosium or europium provide one of pieces of evidence that the $\mathrm{Dy}^{3+}$ and $\mathrm{Eu}^{3+}$ is doped in the as-prepared samples respectively. For the determination of optical band gap, the Kubelka-Munk (K-M) function $^{40), 41)}$ and Tauc plot ${ }^{42)}$ were used. A very slight change in the absorption edge in the spectra was observed. The optical band-gap values of the aeschynite-type samples doped with $\mathrm{Dy}^{3+}$ and $\mathrm{Eu}^{3+}$ were in the range around 3.5$3.6 \mathrm{eV}$. 


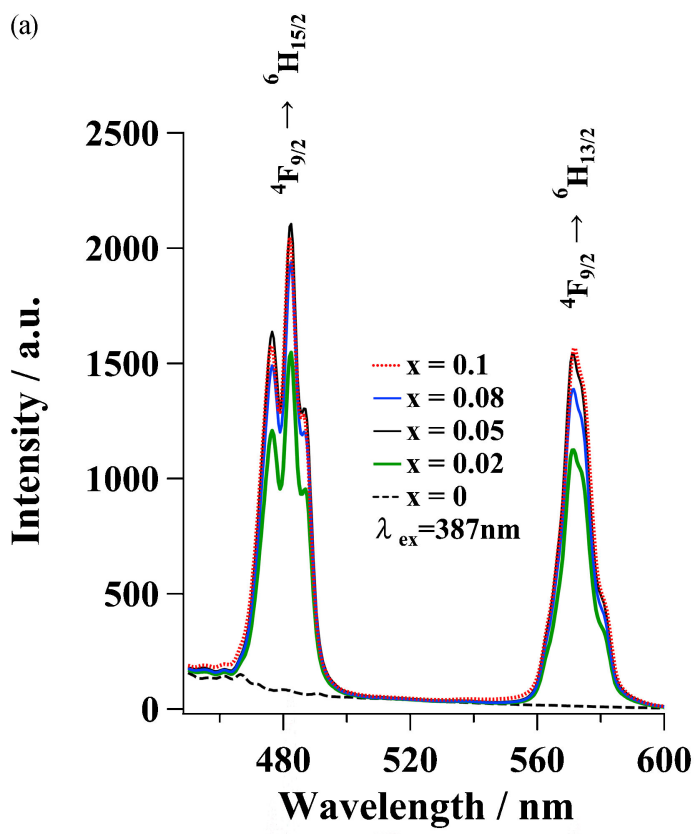

(b)
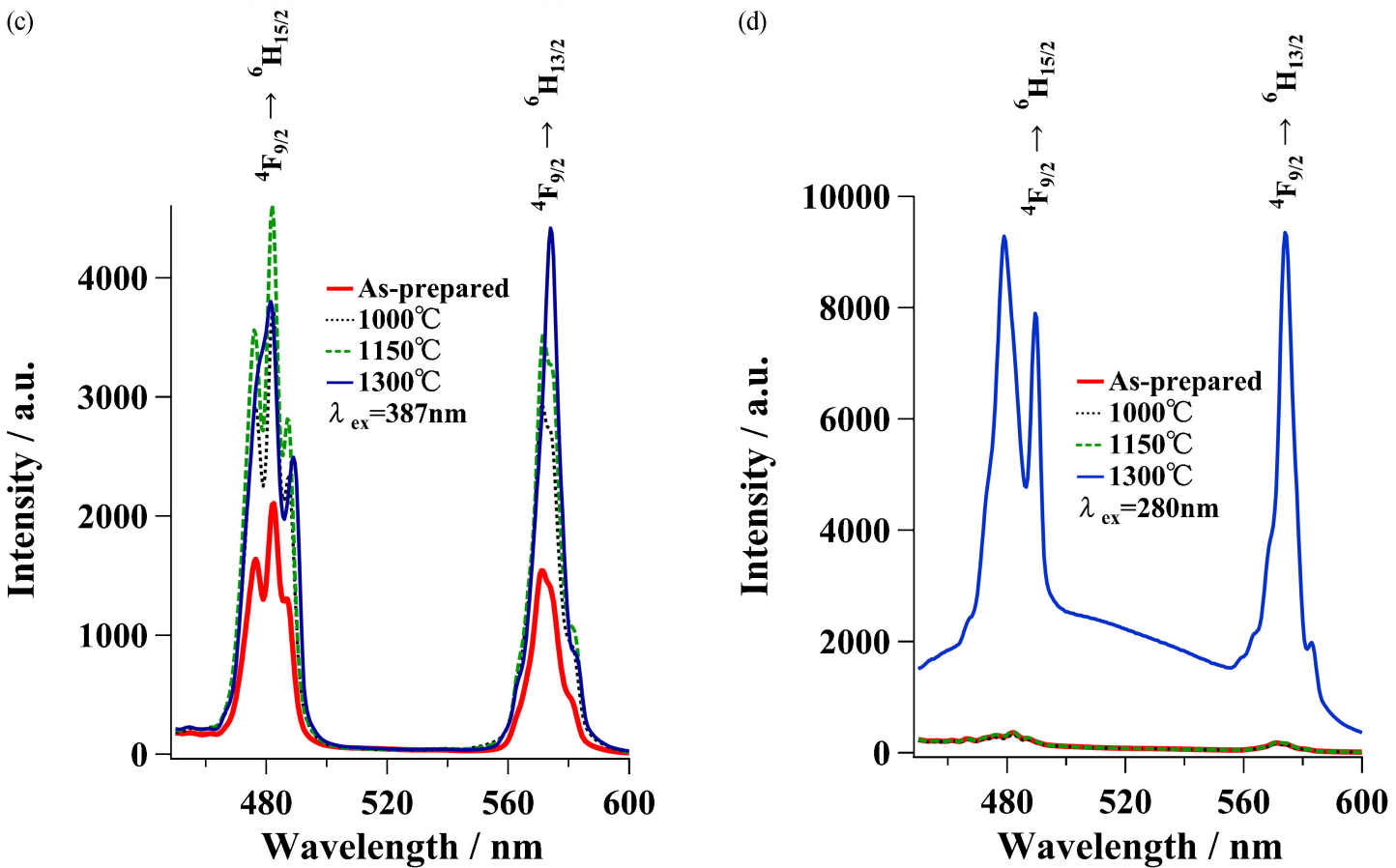

Fig. 9. (a) PL emission spectra measured under excitation at $387 \mathrm{~nm}$ for $\mathrm{Dy}_{x} \mathrm{Gd}_{1.00-x} \mathrm{TiNbO}_{6}$ formed under hydrothermal conditions in the presence of aqueous ammonia at $240^{\circ} \mathrm{C}$ for $24 \mathrm{~h}$. (b) Relationship between $\mathrm{Dy}^{3+}$ concentration, $x$ and PL $\left({ }^{4} F_{9 / 2} \rightarrow{ }^{6} H_{15 / 2}\right)$ emission intensity measured under excitation at 280,350, and $387 \mathrm{~nm}$ for as-prepared $\mathrm{Dy}_{x} \mathrm{Gd}_{1.00-x} \mathrm{TiNbO}_{6}$. PL emission spectra measured under excitation at (c) 387 and (d) $280 \mathrm{~nm}$ for $\mathrm{Dy}_{0.50} \mathrm{Gd}_{0.95} \mathrm{TiNbO}_{6}$ as-prepared and after heating at $1000-1300^{\circ} \mathrm{C}$ for $1 \mathrm{~h}$ in air.

The excitation spectra of the as-prepared aeschynitetype $\mathrm{Dy}_{x} \mathrm{Gd}_{1.00-x} \mathrm{TiNbO}_{6}, x=0-0.10$ and $\mathrm{Eu}_{x} \mathrm{Gd}_{1.00-x^{-}}$ $\mathrm{TiNbO}_{6}, x=0-1.00$ samples measured by monitoring at $\lambda_{\mathrm{em}}=483$ and $611 \mathrm{~nm}$ are shown in Figs. 8(a) and 8(b), respectively. A broad band appearing at around 280-320 $\mathrm{nm}$ is attributed to a charge transfer band (C.T.B.) for the host aeschynite-type crystal. Several high intense and sharp absorption bands attributed to the characteristic intra-4f transitions, i.e., the ${ }^{6} H_{15 / 2} \rightarrow{ }^{6} P_{7 / 2},{ }^{6} P_{5 / 2},{ }^{4} I_{13 / 2}$,
${ }^{4} G_{11 / 2},{ }^{4} I_{15 / 2}$ transitions of Dy ${ }^{3+}$ ions and the ${ }^{7} F_{0} \rightarrow{ }^{5} D_{4}$, ${ }^{5} L_{7},{ }^{5} L_{6},{ }^{5} D_{3},{ }^{5} D_{2}$ transitions of $\mathrm{Eu}^{3+}$ ions are appeared in the spectra of the samples doped with $\mathrm{Dy}^{3+}$ and $\mathrm{Eu}^{3+}$, respectively. These measurement results suggest that those materials can be effectively excited using the UV light at 350 and visible light at $387 \mathrm{~nm}$ corresponding to the ${ }^{6} H_{15 / 2} \rightarrow{ }^{6} P_{7 / 2}$ and ${ }^{6} H_{15 / 2} \rightarrow{ }^{4} I_{13 / 2}$ transitions of $\mathrm{Dy}^{3+}$, respectively and using the visible light at $394 \mathrm{~nm}$ corresponding to the ${ }^{7} F_{0} \rightarrow{ }^{5} L_{6}$ transition of $\mathrm{Eu}^{3+}$, for example, 
in addition to UV-B light corresponding to the C.T.B. for the host crystal.

The PL emission spectra of $\mathrm{Dy}_{x} \mathrm{Gd}_{1.00-x} \mathrm{TiNbO}_{6}, x=$ $0-0.10$ are recorded in the range of $400-650 \mathrm{~nm}$ under excitation at 280,350 , and $387 \mathrm{~nm}$ corresponding to the C,T,B., the ${ }^{6} H_{15 / 2} \rightarrow{ }^{6} P_{7 / 2}$, and ${ }^{6} H_{15 / 2} \rightarrow{ }^{4} I_{13 / 2}$ transitions of $\mathrm{Dy}^{3+}$, respectively. Figure 9(a) shows the PL emission spectra measured under excitation at $387 \mathrm{~nm}$ for the asprepared $\mathrm{Dy}_{x} \mathrm{Gd}_{1.00-x} \mathrm{TiNbO}_{6}, x=0-0.10$ samples. In the spectrum there are mainly two dominating groups of lines lying in blue and yellow region centered at around 480 and $575 \mathrm{~nm}$, respectively. The blue emission bands at $480 \mathrm{~nm}$ are attributed to the ${ }^{4} F_{9 / 2} \rightarrow{ }^{6} H_{15 / 2}$ transition corresponding to magnetic dipole transition, whereas the yellow emission bands at $575 \mathrm{~nm}$ are attributed to the ${ }^{4} F_{9 / 2} \rightarrow{ }^{6} H_{13 / 2}$ transition, which is a hypersensitive electric dipole transition of $\mathrm{Dy}^{3+}$. Both depend on the chemical environment of $\mathrm{Dy}^{3+}$ ion. Therefore the ratio of yellow to blue emission depends on host material. In Fig. 9(a), the yellow/blue emission intensity ratio is found to be almost constant with variation in $\mathrm{Dy}^{3+}$ ion concentration in the same aeschynite-type host crystal. The variation of PL emission intensity with varying $\mathrm{Dy}^{3+}$ ion concentration in the aeschynitetype $\mathrm{GdTiNbO}_{6}$ lattice is presented in Fig. 9(b). The improvement in PL emission intensity for as-prepared samples associated to both blue as well as yellow emission bands with increment in $\mathrm{Dy}^{3+}$ ion concentration is visible up to $5 \mathrm{~mol} \%$. The occurrence of the possible nonradiative cross-relaxation among various $\mathrm{Dy}^{3+}$ ions at above this concentration causes the cancel of the generation of ${ }^{4} F_{9 / 2}$ site of $\mathrm{Dy}^{3+}$, which may be responsible for the concentration quenching phenomenon.

The PL emission spectra measured under excitation at 387 and $280 \mathrm{~nm}$ for the as-prepared sample doped with 5 $\mathrm{mol} \% \mathrm{Dy}^{3+}$ and those samples after heating at 1000, 1150, and $1300^{\circ} \mathrm{C}$ for $1 \mathrm{~h}$ in air corresponding to the XRD patterns shown in Fig. 7 are presented in Figs. 9(c) and 9(d), respectively. When fine-grained materials consisting of crystalline metal oxides are exposed to high temperatures less than melting temperature in air, a decrease in specific surface area, crystal growth, enhancement in crystallinity, grain growth, or sintering are brought about, in general, ${ }^{43), 44)}$ and the size measurement of large crystallite more than $100 \mathrm{~nm}$ using XRD line broadening becomes impossible. After high-temperature heating in air, defects or impurities that may act as luminescent quenchers such as $\mathrm{OH}^{-}$species, which might be included in hydrothermal precipitates, might have been removed. ${ }^{45}$ Although relatively high PL emission intensity was obtained for the asprepared $\mathrm{Dy}_{0.50} \mathrm{Gd}_{0.95} \mathrm{TiNbO}_{6}$ sample under excitation by means of direct excitation using $387 \mathrm{~nm}$ (the ${ }^{6} H_{15 / 2} \rightarrow$ ${ }^{4} I_{13 / 2}$ transition of $\left.\mathrm{Dy}^{3+}\right)$, the PL emission intensity gradually increased with increasing heating temperature in air, which may be due to the enhancement in crystallinity and in purity of materials. In the spectrum of the sample after heating at $1300^{\circ} \mathrm{C}$, the change in the yellow/blue emission intensity ratio is also observed, which may be related to the change in the environment of $\mathrm{Dy}^{3+}$ ion in the host lattice

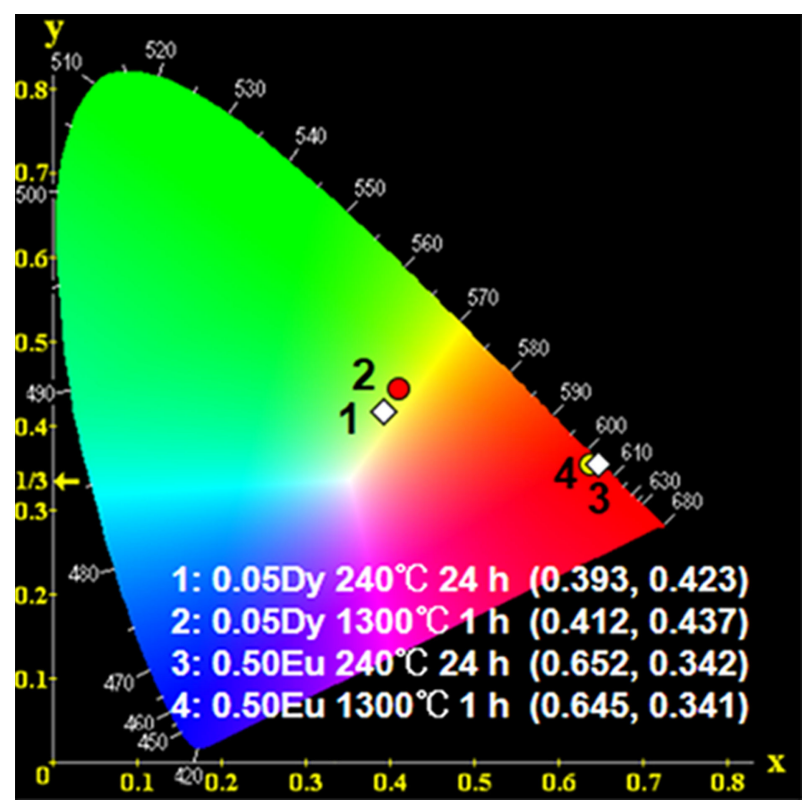

Fig. 10. The CIE chromaticity coordinates $x$ and $y$ for the PL emission of the as-prepared aeschynite-type $\mathrm{Dy}_{0.05} \mathrm{Gd}_{0.95} \mathrm{TiNbO}_{6}$ and $\mathrm{Eu}_{0.50} \mathrm{Gd}_{0.50} \mathrm{TiNbO}_{6}$ samples as-prepared and after heating at $1300^{\circ} \mathrm{C}$ for $1 \mathrm{~h}$ in air evaluated under excitation at 387 and $394 \mathrm{~nm}$, respectively.

caused by the phase transformation from aeschynite to euxenite structure (as shown in Fig. 7). The PL emission spectra measured under excitation at $280 \mathrm{~nm}$ [Fig. 9(d)] shows that heating the $\mathrm{Dy}^{3+}$-doped $\mathrm{GdTiNbO}_{6}$ sample at $1300^{\circ} \mathrm{C}$ in air enhances dramatically its blue and yellow emission intensities involved in the broad host emission especially in the case under indirect excitation using energy transfer from the host absorption band at $280 \mathrm{~nm}$. The color chromaticity coordinates $x$ and $y$ for the emission of the as-prepared aeschynite-type $\mathrm{Dy}_{0.05} \mathrm{Gd}_{0.95} \mathrm{TiNbO}_{6}$ samples as-prepared and after heating at $1300^{\circ} \mathrm{C}$ in air evaluated under direct excitation at $387 \mathrm{~nm}$ were $x=0.393$, $y=0.423$ and $x=0.412, y=0.437$, respectively, which fall in a green-yellow region of the CIE-1931 chromaticity diagram (Fig. 10, No. 1 and 2).

Using the $\mathrm{Eu}^{3+}$-doped $\mathrm{GdTiNbO}_{6}$ samples the effect of hydrothermal processing conditions, that is, the crystallinity of products on the luminescence property was investigated, on the other hand. Figure 11(a) shows the PL emission spectra measured under excitation at $395 \mathrm{~nm}$ (corresponding to the ${ }^{7} F_{0} \rightarrow{ }^{5} L_{6}$ transition of $\mathrm{Eu}^{3+}$ ) for the as-prepared aeschynite-type $\mathrm{Eu}_{0.50} \mathrm{Gd}_{0.50} \mathrm{TiNbO}_{6}$ samples formed by hydrothermal treatment in the presence of aqueous ammonia or urea for 5 or $24 \mathrm{~h}$. The PL emission spectra are mainly composed of the ${ }^{5} D_{0} \rightarrow{ }^{7} F_{J}(J=0,1$, 2) transition lines of $\mathrm{Eu}^{3+}$, i.e., weak orange emission lines $\left({ }^{5} D_{0} \rightarrow{ }^{7} F_{1}\right.$ transition) and strong red emission lines $\left({ }^{5} D_{0} \rightarrow{ }^{7} F_{2}\right.$ transition). The PL emission intensity of the as-prepared aeschynite-type $\mathrm{Eu}_{0.50} \mathrm{Gd}_{0.50} \mathrm{TiNbO}_{6}$ prepared using aqueous ammonia was stronger than that using urea, and it clearly increased with increase in the hydrothermal treatment time, which was well corresponded to the 
(a)
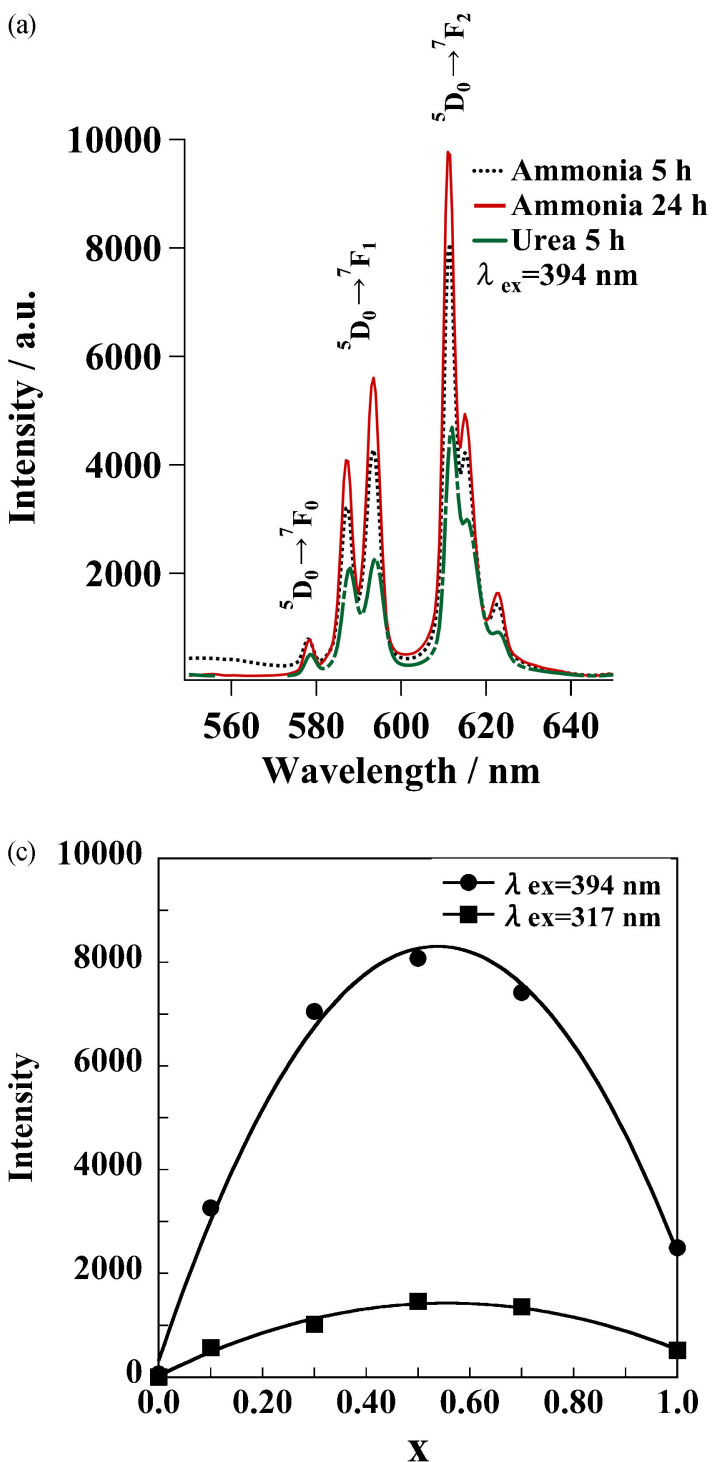

(b)

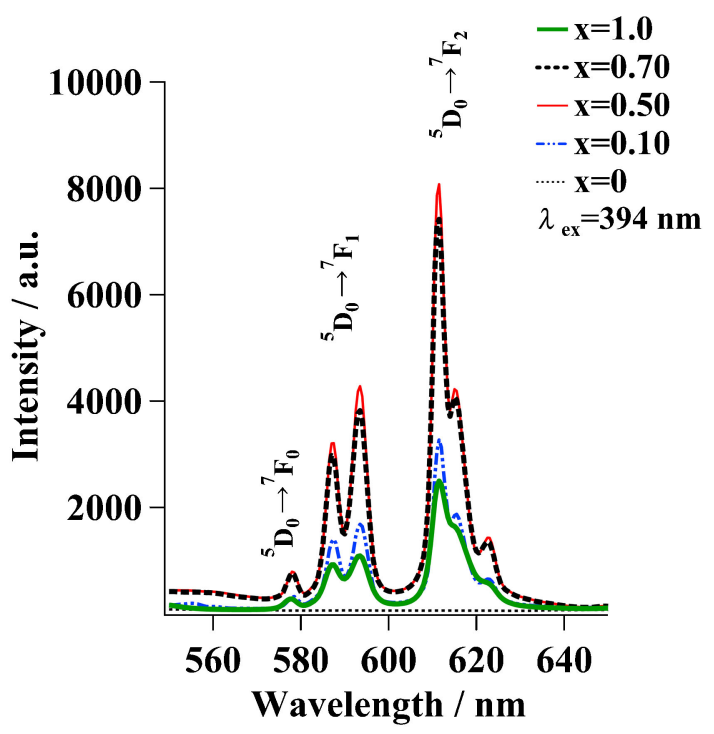

Fig. 11. PL emission spectra measured under excitation at (a) $394 \mathrm{~nm}$ for $\mathrm{Eu}_{0.50} \mathrm{Gd}_{0.50} \mathrm{TiNbO}_{6}$ formed under hydrothermal conditions in the presence of urea or aqueous ammonia at $240{ }^{\circ} \mathrm{C}$ for 5 or $24 \mathrm{~h}$ and those measured under excitation at (b) $394 \mathrm{~nm}$ for $\mathrm{Eu}_{x} \mathrm{Gd}_{1.00-x} \mathrm{TiNbO}_{6}$ formed under hydrothermal conditions in the presence of aqueous ammonia at $240^{\circ} \mathrm{C}$ for $5 \mathrm{~h}$. (c) Relationship between $\mathrm{Eu}^{3+}$ concentration, $x$ and $\mathrm{PL}\left({ }^{5} \mathrm{D}_{0} \rightarrow{ }^{7} \mathrm{~F}_{2}\right)$ emission intensity measured under excitation at 317 and $394 \mathrm{~nm}$ for as-prepared $\mathrm{Eu}_{x} \mathrm{Gd}_{1.00-x} \mathrm{TiNbO}_{6}$.

increase in their crystallinity (i.e. crystallite size) as shown in Figs. 1, 5, and Table 1. It is certain that to improve crystallinity brought about the enhancement in the PL emission intensity.

The $\mathrm{Eu}^{3+}$ concentration dependence of PL property was investigated for the samples formed at 240 for $5 \mathrm{~h}$. The PL emission spectra of the as-prepared $\mathrm{Eu}_{x} \mathrm{Gd}_{1.00-x} \mathrm{TiNbO}_{6}$ evaluated under excitation at $394 \mathrm{~nm}$ (corresponding to the ${ }^{7} F_{0} \rightarrow{ }^{5} L_{6}$ transition of $\mathrm{Eu}^{3+}$ ) are shown in Fig. 11(b). The PL emission intensities of the ${ }^{5} D_{0} \rightarrow{ }^{7} F_{2}$ transition in the spectra evaluated under excitation both at $317 \mathrm{~nm}$ and at $394 \mathrm{~nm}$ are plotted against the concentration of $\mathrm{Eu}^{3+}, x$ in Fig. 11(c). In the case of as-prepared samples, the PL emission intensities of the $\mathrm{f}-\mathrm{f}$ transitions of $\mathrm{Eu}^{3+}$ in the system $\left(\mathrm{Eu}_{x} \mathrm{Gd}_{1.00-x} \mathrm{TiNbO}_{6}\right)$ measured under direct excitation using $394 \mathrm{~nm}$ (the ${ }^{7} F_{0} \rightarrow{ }^{5} L_{6}$ transition of $\mathrm{Eu}^{3+}$ ion) [in Fig. 11(b)] were nearly four times stronger than those obtained under indirect excitation, i.e. indirect energy transfer from the host absorption band using $317 \mathrm{~nm}$. Although the $\mathrm{Nb}(\mathrm{Ti}) \mathrm{O}_{6}$ polyhedron can absorb excitation energy corresponding to $317 \mathrm{~nm}$ and can transfer the energy to the neighboring activator $\mathrm{Eu}^{3+}$ ions, it is noted that the as-prepared (Eu,Gd)TiNbO 6 materials obtained hydrothermally can be excited effectively by direct excitation. In the case using indirect excitation and energy transfer from the host absorption band, we have already reported about the effect of heating in air on the PL emission and phase transition of $\mathrm{GdTiNbO}_{6}: \mathrm{Eu}^{3+} .{ }^{39)}$ As the $\mathrm{Eu}^{3+}$ concentration increased, the emission intensity of the asprepared $\mathrm{Eu}_{x} \mathrm{Gd}_{1.00-x} \mathrm{TiNbO}_{6}$ gradually increased, reached a maximum value at $x=0.50$, and then decreased in both cases as shown in Fig. 11(c). It is evident that the emission 


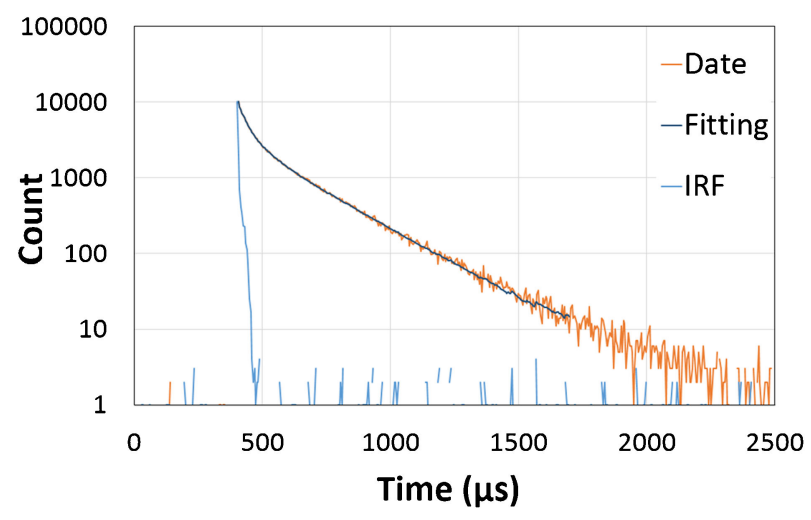

Fig. 12. Decay lifetime of as-prepared aeschynite-type Dy $\mathrm{y}_{0.05}$ $\mathrm{Gd}_{0.95} \mathrm{TiNbO}_{6}$ for the emission band at $483 \mathrm{~nm}$ measured under excitation at $365 \mathrm{~nm}$.

intensity of the $\mathrm{Eu}_{x} \mathrm{Gd}_{1.00-x} \mathrm{TiNbO}_{6}$ solid solution becomes the strongest by the incorporation of $50 \mathrm{~mol} \% \mathrm{Eu}^{3+}(x=$ $0.50)$. The color chromaticity coordinates $x$ and $y$ for the emission of the as-prepared aeschynite-type $\mathrm{Eu}_{0.50} \mathrm{Gd}_{0.50^{-}}$ $\mathrm{TiNbO}_{6}$ samples as-prepared and after heating at $1300^{\circ} \mathrm{C}$ in air evaluated under direct excitation at $394 \mathrm{~nm}$ were $x=$ $0.652, y=0.342$ and $x=0.645, y=0.341$, respectively, which lies in a slight orangey red region of the CIE-1931 chromaticity diagram (Fig. 10, No. 3 and 4).

The Judd-Ofelt theory shows that the electric dipole transitions $\left({ }^{5} D_{0} \rightarrow{ }^{7} F_{2}\right)$ are sensitive to the local electric field and they are only allowed in the absence of inversion symmetry. ${ }^{46), 47)}$ When $\mathrm{Eu}^{3+}$ ions are situated in a site without inversion symmetry, the ${ }^{5} D_{0} \rightarrow{ }^{7} F_{2}$ electric-dipole transition is the strongest. ${ }^{48)}$ Because the ${ }^{5} D_{0} \rightarrow{ }^{7} F_{2}$ transition is dominant in these results [in Figs. 11(a) and 11(b)], $\mathrm{Eu}^{3+}$ ions are located in a site without inversion symmetry in the (Eu,Gd) $\mathrm{TiNbO}_{6}$ materials. The absolute quantum yield measured for the as-prepared samples is also shown in Table 1 . The values of the absolute quantum yield of the asprepared $\mathrm{Eu}_{0.50} \mathrm{Gd}_{0.50} \mathrm{TiNbO}_{6}$ (: Ammonia $5 \mathrm{~h}$ ) measured under excitation at 394 and $464 \mathrm{~nm}$ were 37 and 30\%, respectively. Note that the as-prepared $\mathrm{GdTiNbO}_{6}$ doped with $\mathrm{Eu}^{3+}$ showed strong red emission without subsequent heat treatment in air.

Heat-treatment at temperatures higher than $1000^{\circ} \mathrm{C}$ in air is reported to be necessary for the crystallization and synthesis of $\mathrm{RETiNbO}_{6}$ compounds using conventional techniques, e.g., solid-state reaction, in general. ${ }^{9)}$ Hence these results in this study suggest that the present technique is beneficial and moreover important from the view point of processing through energy consumption reduction, "green processing". Figure 12 shows the fluorescence decay kinetic for the $483 \mathrm{~nm}$ emission of the asprepared aeschynite-type sample $\mathrm{Dy}_{0.05} \mathrm{Gd}_{0.95} \mathrm{TiNbO}_{6}$ measured under direct excitation at $365 \mathrm{~nm}$. The decay lifetime (for the emission band at $483 \mathrm{~nm}$ ) of $\mathrm{Dy}_{0.05} \mathrm{Gd}_{0.95^{-}}$ $\mathrm{TiNbO}_{6}$ as-prepared and after $1300^{\circ} \mathrm{C}$ was determined to be 162 and $156 \mu \mathrm{s}$, respectively. The decay lifetime (for the emission band at $615 \mathrm{~nm}$ ) of the aeschynite-type $\mathrm{Eu}_{0.5} \mathrm{Gd}_{0.50} \mathrm{TiNbO}_{6}$ as-prepared and after $1300^{\circ} \mathrm{C}$ mea- sured under direct excitation at $405 \mathrm{~nm}$ was found to be 570 and $571 \mu \mathrm{s}$, respectively, on the other hand.

\section{Conclusions}

Aeschynite-type fine crystals with high crystallinity were formed directly as solid solutions in the $\mathrm{Dy}_{x} \mathrm{Gd}_{1-x} \mathrm{TiNbO}_{6}$ and $\mathrm{Eu}_{x} \mathrm{Gd}_{1-x} \mathrm{TiNbO}_{6}$ systems from weak basic precursor solutions using $\mathrm{Dy}\left(\mathrm{NO}_{3}\right)_{3}, \mathrm{EuCl}_{3}, \mathrm{GdCl}_{3}, \mathrm{TiOSO}_{4}$, and $\mathrm{NbCl}_{5}$ under hydrothermal conditions at $240^{\circ} \mathrm{C}$ for $5-24 \mathrm{~h}$. The aeschynite-type crystals formed hydrothermally in the presence of aqueous ammonia were well-crystallized and micron-sized. Submicron-sized finer aeschynite crystals were formed when using the hydrolysis of urea, on the other hand, which is suggested to be due to an increase in the nucleation number for the crystallization of aeschynite. The aeschynite-type $\mathrm{GdTiNbO}_{6}: \mathrm{Dy}^{3+}$ showed blue and yellow PL emissions attributed to the ${ }^{4} F_{9 / 2} \rightarrow{ }^{6} H_{15 / 2}$ and ${ }^{4} F_{9 / 2} \rightarrow{ }^{6} H_{13 / 2}$ transitions of $\mathrm{Dy}^{3+}$ ion, respectively. The aeschynite-type $\mathrm{GdTiNbO}_{6}: \mathrm{Eu}^{3+}$ presented characteristic weak orange and strong red PL emissions corresponding to the ${ }^{5} D_{0} \rightarrow{ }^{7} F_{1}$ and ${ }^{5} D_{0} \rightarrow{ }^{7} F_{2}$ transitions of $\mathrm{Eu}^{3+}$ ion, respectively. The PL emission intensity of aeschynite crystals increased with increasing in their crystallinity, which was closely related to their processing conditions. The asprepared aeschynite-type $\mathrm{Dy}_{0.05} \mathrm{Gd}_{0.95} \mathrm{TiNbO}_{6}$ and $\mathrm{Eu}_{0.50^{-}}$ $\mathrm{Gd}_{0.50} \mathrm{TiNbO}_{6}$ provided the strongest PL emission intensity under direct excitation of dopant ions without subsequent heat treatment in air.

Acknowledgments This work was supported in part by a Grant-in-Aid for Scientific Research (B) (17H03098) from the Ministry of Education, Culture, Sports, Science, and Technology, Japan.

\section{References}

1) R. Mani, S. N. Achary, K. R. Chakraborty, S. K. Deshpande, J. E. Joy, A. Nag, J. Gopalakrishnan and A. K. Tyagi, J. Solid State Chem., 183, 1380-1387 (2010).

2) K. P. Surendran, S. Solomon and M. R. Varma, J. Mater. Res., 17, 2561-2566 (2002).

3) R. Mani, S. N. Achary, K. R. Chakraborty, S. K. Deshpande, J. E. Joy, A. Nag, J. Gopalakrishnan and A. K. Tyagi, Adv. Mater., 20, 1348-1352 (2008).

4) L. Jacob, H. P. Kumar, K. G. Gopchandran, J. K. Thomas and S. Solomon, J. Mater. Sci. Mater. Electron., 18, 831-835 (2007).

5) V. V. Kazantsev, E. I. Krylov, A. K. Borisov and A. I. Chupin, Russ. J. Inorg. Chem., 19, 506-507 (1974).

6) C. H. Holcombe, J. Mater. Sci., 14, 2255-2260 (1979).

7) G. Blasse, Mater. Res. Bull., 2, 497-502 (1967).

8) M. T. Sebastian, R. Ratheesh, H. Sreemoolanathan, S. Solomon and P. Mohanan, Mater. Res. Bull., 32, 12791284 (1997).

9) M. T. Sebastian, S. Solomon, R. Ratheesh, J. George and P. Mohanan, J. Am. Ceram. Soc., 84, 1487-1489 (2001).

10) S. Solomon, M. Kumar, K. P. Surendran, M. T. Sebastian and P. Mohanan, Mater. Chem. Phys., 67, 291-293 (2001). 
11) D. B. Dhwajam, J. K. Thomas, K. Joy and S. Solomon, J. Mater. Sci.-Mater. El., 22, 384-388 (2011).

12) X. Qi, T. P. J. Han, H. G. Gallagher, B. Henderson, R. Illingworth and I. S. Ruddock, J. Phys. Condens. Matter, 8, 4837-4845 (1996).

13) X. Qi, R. Illingworth, H. G. Gallagher, T. P. J. Han and B. Henderson, J. Cryst. Growth, 160, 111-118 (1996).

14) G. Blasse, J. Inorg. Nucl. Chem., 28, 1122-1124 (1966).

15) B. V. Shul'gin, A. K. Borisov, E. I. Krylov, V. K. Slepukhin and V. I. Rogovich, Zh. Prikl. Spektrosk., 15, 431-435 (1971).

16) Q. Ma, Y. Zhou, A. Zhang, M. Lu, G. Zhou and C. Li, Solid State Sci., 11, 1124-1130 (2009).

17) Q. Ma, M. Lu, P. Yang, A. Zhang and Y. Cao, J. Lumin., 29, 386-392 (2014).

18) A. K. Bedyal, V. Kumar and H. C. Swart, J. Alloy Compd., 709, 362-372 (2017).

19) P. Du and J. S. Yu, J. Lumin., 179, 451-456 (2016).

20) K. Lingadurai, B. Sundarakannan, E. R. Nagarajan, H Kominami, Y. Nakanishi and M. Kottaisamy, J. Lumin., 177, 249-253 (2016).

21) Y. Cao, X. Ding and Y. Wang, J. Am. Ceram. Soc., 99, 3696-3704 (2016).

22) D. J. Naczynski, M. C. Tan, R. E. Riman and P. V. Moghe, J. Mater. Chem. B, 2, 2958-2973 (2014).

23) C. Wang, S. Ye, Y. Li and Y. Q. Zhang, J. Appl. Phys., 121, 123105 (2017)

24) K. P. Surendran, M. R. Varma, P. Mohanan and M. T. Sebastian, J. Am. Ceram. Soc., 86, 1695-1699 (2003).

25) V. V. Deshpande and K. R. Rao, Curr. Sci., 23, 668-669 (1968).

26) Y. Lei, I. M. Reaney, Y. C. Liu, Y. S. Yin and G. H. Chen, Adv. Mat. Res., 197-198, 285-289 (2011).

27) F. John, A. John, J. K. Thomas and S. Solomon, J. Mater. Sci-Mater. El., 24, 1-11 (2017).

28) M. Hirano and S. Sato, J. Am. Ceram. Soc., 99, 26072614 (2016).
29) M. Hirano and M. Hara, J. Ceram. Soc. Jpn., 126, 178183 (2018).

30) Y. Takada, K. I. Mimura and K. Kato, J. Ceram. Soc. Jpn., 126, 326-330 (2018).

31) Y. Hattori, I. Fujii, S. Ootsuki, M. Furukawa, S. Wada and S. Ueno, J. Ceram. Soc. Jpn., 126, 306-310 (2018).

32) M. Hirano, K. Sakoda, K. Souma, H. Nishimoto, K. Jinno and Y. Hirose, Ceram. Int., 41, 14285-14292 (2015).

33) M. Hirano and K. Ishikawa, J. Am. Ceram. Soc., 100, 2814-2821 (2017).

34) M. Hirano and T. Ohmori, J. Am. Ceram. Soc., 98, 3726-3732 (2015).

35) N. Li, J. Y. Si, G. M. Gai and Y. Tao, RSC $A d v$., 6, 50797-50807 (2016).

36) V. B. Aleksandrov, Dokl. Akad. Nauk SSSR, 142, 181184 (1963) (in Russian).

37) P. S. Chang, Sci. Sin. Ser. B, 12, 2337-2343 (1963).

38) R. D. Shannon, Acta Crystallogr. A, 32, 751-767 (1976).

39) M. Hirano and Y. Takagi, Mater. Res. Bull., 105, 13-20 (2018).

40) P. Kubelka and F. Munk, Z. Tech. Phys., 12, 593-601 (1931).

41) P. Kubelka, J. Opt. Soc. Am., 38, 448-457 (1948).

42) J. Tauc, Mater. Res. Bull., 3, 37-46 (1968).

43) M. Hirano, K. Ota and H. Iwata, Chem. Mater., 16, 3725-3732 (2004).

44) M. Hirano and N. Sakaida, J. Am. Ceram. Soc., 85, 1145-1150 (2002).

45) M. Hirano and K. Ishikawa, J. Photoch. Photobio. A, 316, 88-94 (2016).

46) B. R. Judd, Phys. Rev., 127, 750-761 (1962).

47) G. S. Ofelt, J. Chem. Phys., 37, 511-520 (1962).

48) G. Blasse, J. A. L. E. Karl and A. Gschneidner, "Handbook on the Physics and Chemistry of Rare Earth", Elsevier, Amsterdam (1979). 